Nama : Rosi Oktaviana

NRP : 130117047

Mata Kuliah/KP : Strategi Internasional/A

\title{
Strategi Internasional : Global Value Chain, Strategic Alliance, dan Social Enterprise
}

\begin{abstract}
Paper ini bertujuan untuk memahami beberapa strategi internasional dalam pengelolaannya untuk dapat bertahan dalam pasar Indonesia. Menggunakan tiga kasus berbeda antara lain produksi rotan, industri medis, dan social enterprise. Halhal yang dibahas lebih lanjut antara ketiganya adalah mengapliksikan global value chain menggunakan supply chain management pada industri rotan, strategi aliansi untuk wholly owned subsidiary pada industri medis dengan dua fokus utama strategi aliansi yaitu license agreement dan joint venture, dan yang terakhir promosi pada social enterprise. Strategi internasional dalam pengaplikasiannya masih harus menyesuaikan dengan kondisi lokal dan mewajibkan perusahaan memahami regulasi yang ada. Dengan pengaplikasian yang tepat sebagai bentuk inovasi dalam usaha, strategi internasional ini diterapkan dengan tujuan untuk meningkatkan kesejahteraan ekonomi di Indonesia.
\end{abstract}

\section{Global Value Chain in Rattan Industry}

Produksi khas wilayah negara yang diimpor atau diekspor sangat dipengaruhi oleh keputusan beberapa merek global dan produsen kontrak utama mereka. Manfaat dari konsentrasi produksi di negara adalah memperluas pasar, dan pada saat yang sama, kemampuan mereka memperluas pasar memungkinkan perusahaan mampu memimpin global meminta produksi lebih ke negara-negara tersebut (Lee \& Gereffi, 2015). Di Indonesia rotan adalah salah satu produk khusus wilayah negara yang mempunyai potensi dikembangkan. Rotan adalah contoh yang bagus dari produk non- 
kayu hutan (Non Timber Forest Product : NTFP), yang memberikan peluang untuk menyelamatkan hutan di negara-negara berkembang. Tidak seperti bambu, yang tumbuh hampir seperti pohon, rotan merupakan tanaman merambat yang menyerupai batang mawar. Tumbuh dari bagian bawah hutan, menggunakan pohon untuk mendaki ke atas, dan biasanya dipanen oleh petani rotan saat berusia beberapa tahun. Kebijakan membuat para pemangku kepentingan melakukan beberapa pekerjaan pada mempromosikan inclusive global value chain (IGVC) di bawah manajemen yang bertanggung jawab, yang melibatkan masyarakat hutan dan memungkinkan pengembangan sosio-ekonomi yang berkelanjutan. (Pratono A. H., 2019).

Global value chain (GVC) telah menjadi bagian integral dari ekonomi global, membentuk kembali pola tradisional produksi dan perdagangan internasional (Lee \& Gereffi, 2015). GCV menambah kegiatan produksi terdesentralisasi (perdagangan serta investasi) perusahaan. Konseptualisasi dari GVC seperti yang digambarkan bisa diartikan berbagai kegiatan yang terlibat di bawah kategori yang luas mencakup "transportasi fisik," "fasilitasi perdagangan," dan "layanan logistik" (Ishido, 2017). GVC diharapkan dapat memberikan kesempatan kerja kepada masyarakat yang kurang diperhatikan, seperti masyarakat hutan, pengrajin lokal dan desainer muda di negara-negara berkembang (Pratono A. H., 2019). Konsep GVC bukan hanya tentang konektivitas fisik tetapi juga tentang konektivitas kelembagaan dan berorientasi bisnis, dalam kasus pemasok skala kecil, mereka kurang bersedia untuk menjadi bagian dari GVC terutama karena kurangnya informasi yang diperlukan (Ishido, 2017).

Berbagi informasi mengacu pada sejauh mana informasi non-publik dikomunikasikan sepanjang rantai pasokan (Hamister, 2012). Setiap perbuatan perusahaan yang salah dalam rantai pasokan mereka akhirnya bisa menimbulkan kerusakan reputasi. Beberapa cara mennganinya adalah dengan local knowledge yang lebih atau model bisnis unik cocok untuk pasar negara berkembang. Pada saat yang sama, tanpa pengembangan lebih lanjut, keunggulan kompetitif tersebut 
mungkin singkat atau hanya berkelanjutan dengan mengorbankan memburuknya kondisi tenaga kerja bagi pekerja yang terpinggirkan (Lee \& Gereffi, 2015).

Praktek Supply Chain Management (SCM) adalah tindakan-tindakan manajerial yang dilakukan untuk meningkatkan kinerja rantai pasokan terpadu. Pelaksanaan praktek SCM pada pengusaha kecil memiliki efektivitas yang sama seperti yang telah di sektor ekonomi lainnya yang telah menerima lebih banyak perhatian dari kedua praktisi dan akademisi rantai pasokan (Hamister, 2012). Dengan SCM yang benar memungkinkan GCV untuk dijalankan pada industri rotan, karena melihat informasi sebagai salah satu faktor penting dalam GCV.

\section{Wholly Owned Subsidiary in Medhical Industry}

Pemerintah Indonesia mendorong perusahaan multinasional untuk berinvestasi dalam produksi perangkat medis kesehatan di Indonesia, yang dapat membentuk sebuah kolaborasi berbasis ekuitas atau merger dan strategi akuisisi (Pratono \& Ratih, 2019). Kolaborasi berbasis ekuitas dan strategi akuisisi adalah salah satu dari strategi aliansi. Strategi aliansi menawarkan alternatif untuk perusahaan, dimana mereka bisa bergabung dengan perusahaan-perusahaan lain dalam mengejar peluang yang seharusnya berada di luar kemampuan perusahaan saat ini. Pada intinya, aliansi memungkinkan mitra perusahaan untuk kreatif menggabungkan sumber daya dalam pembentukan keunggulan kompetitif bersama (Teng \& Das, 2008).

Di Indonesia, itu adalah wajib bagi manufaktur perangkat medis asing mengekspor produk mereka ke Indonesia untuk mematuhi peraturan yang berlaku. Peraturan ini mewajibkan produsen atau pemasok untuk mendaftarkan produk mereka dengan Departemen Kesehatan Indonesia untuk dicatatkan dalam Pendaftaran Alat Kesehatan Indonesia. Ini bisa menjadi cabang perusahaan di Indonesia dari pemilik produk (produsen) atau perusahaan lokal yang diberi wewenang oleh perusahaanperusahaan multinasional untuk mengajukan aplikasi registrasi produk (Pratono \& Ratih, 2019). Hal ini membuka peluang bagi distributor luar negeri untuk mencoba 
menjalankan bisnis dengan menggunakan jalan aliansi, dengan mencoba menarik rumah sakit lokal untuk menguasai pasar nasional. Hubungan antara strategi bisnis perusahaan dan seleksi kegiatan aliansi memberikan aspek baru dari analisis untuk aliansi strategis, dan juga berguna untuk perusahaan merencanakan portofolio aliansi sebagai ukuran untuk mencapai tujuan bisnis (Veiga \& Franco, 2015). Perusahaan global lebih memilih untuk memimpin integrasi global dalam operasi yang seragam. Aliansi diharapkan dapat mempercepat program pembangunan berdasarkan kemitraan risiko dan pembagian pendapatan (Pratono \& Ratih, 2019).

Kemitraan dengan distributor lokal yang dapat diandalkan adalah perjanjian lisensi Karena ada larangan untuk melakukan penjualan langsung, perjanjian jangka panjang memungkinkan perusahaan multinasional untuk fokus pada strategi pemasaran dan pelayanan serta mengundang distributor tunggal dengan kemampuan yang kuat untuk mengelola seluruh pasar nasional. Pada jenis ini kesepakatan, perusahaan multinasional perlu mengembangkan strategi pemasaran dengan berbagai tingkat pengembangan produk. (Pratono \& Ratih, 2019). Ketika memanfaatkan aset lisensi perusahaan menggunakan aliansi lisensi, eksekutif mungkin akan tergoda untuk percaya bahwa pengalaman akan membantu perusahaan mengembangkan kompetensi di daerah tersebut. Namun, semua bentuk aliansi termotivasi oleh keinginan perusahaan berpartisipasi untuk mencapai beberapa manfaat (Gammoh \& Voss, 2013). Dengan perjanjian lisensi membuat distribusi lokal menjadi bisa dikendalikan dan meminimalkan resiko yang ada dan juga dapat mengelola pasar nasional dengan memakai berbagai tingkat produk.

Mendirikan usaha aliansi ekuitas (joint venture) untuk mengatasi halangan di daerah lokal. Joint venture menanggapi lingkungan yang dinamis dari perlindungan untuk membuka kebijakan dimana perusahaan multinasional mulai memilih akuisisi atau mode entri hijau, yang memungkinkan mereka untuk mengelola operasi global dengan fokus pada produk teknologi rendah, seperti furnitur rumah sakit dan produk pembuangan (Pratono \& Ratih, 2019). Joint venture yang mengembangkan budaya kolektivis mampu mengelola mereka konflik kooperatif, dan pendekatan kooperatif 
ini untuk konflik mempromosikan pembelajaran tim untuk berbagi pengetahuan dan kinerja perusahaan, sedangkan nilai-nilai individualistis menyebabkan kompetitif konflik manajemen dan performa lemah. Dalam kerjasama, mereka percaya tujuan mereka terkait secara positif sehingga sebagai salah satu orang bergerak ke arah pencapaian tujuan, orang lain juga bergerak ke arah mencapai tujuan mereka. Dengan tujuan koperasi, mitra saling membantu sukses (Wong, Wei, \& Wang, 2018). Joint venture akan dapat membuat perusahaan multinasional akan dapat menyesuaikan dengan lingkungan dan dapat menyesuaikan produknya dengan kebijakan dan kesuaian pasar, dan hal hal ini didukung oleh keinginan perusahaan yang bergerak untuk mencapai tujuannya sehingga dapat mengatasi pasar sehingga akhirnya menguasai pasar dengan jenis aliansi ini.

\section{Advertizing Social Enterprise}

Perusahaan sosial (social enterprise) disajikan sebagai pemain kunci dalam reformasi untuk menyapu sektor publik, dan, sebagai alternatif, atau sebagai cara yang berbeda bertukar barang dan jasa berdasarkan nilai-nilai sosial bersama. Menggunakan perusahaan sosial dan struktur mereka untuk imajinatif menuntun ekonomi lokal berdasarkan tujuan meningkatkan kesejahteraan semua orang dalam masyarakat, ekonomi lokal yang tumbuh dapat berkontribusi pada pengembangan masyarakat secara sosial dan ekonomi-sementara pada saat yang sama menjadi bertanggung jawab terhadap lingkungan (Kay, Roy, \& Donaldson, 2016). :

Internasionalisasi social enterprise oleh organisasi menimbulkan pertanyaan bagaimana organisasi non profit dan amal dalam kondisi kelangkaan sumber daya dan menghindari kelembagaan memanfaatkan jaringan mereka dalam proses pembelajaran organisasi. Kolaborasi antara lembaga-lembaga internasional dan organisasi-organisasi lokal di Indonesia dilakukan untuk mengevaluasi proses pembelajaran antar-organisasi, yang menyangkut bisnis inklusif, inovasi, dan transfer teknologi (Pratono, Marciano, \& Suyanto, 2018). 
Banyak usaha kecil Indonesia merupakan perusahaan tradisional dengan produktivitas rendah. Mereka sebagian besar menghasilkan dasar, rendah barang nilai tambah untuk pasar lokal. Fakta bahwa hanya sebagian kecil dari usaha kecil Indonesia menerima kredit dari bank atau lembaga keuangan lainnya merefleksikan bawah mengembangkan pasar keuangan dan lembaga-lembaga di negara ini (Tambunan, 2011). Social enterprise mungkin bergabung dengan beberapa lokakarya yang disediakan oleh organisasi perantara yang berbeda, yang melakukan fungsi menyediakan akses informasi. Bergabung dengan kegiatan internasional yang diperoleh perusahaan sosial yang diamati reputasi sebagai kemampuan untuk meningkatkan akses. perusahaan sosial secara langsung terlibat dalam produksi barang atau penyediaan jasa kepada orang-orang (Pratono, Marciano, \& Suyanto, 2018).Tanpa dukungan, perusahaan sosial akan, dalam semua kemungkinan, tetap marginal. Di sisi lain, dengan dukungan pemerintah, perusahaan sosial mungkin kehilangan nya "esensi” sebagai cara alternatif penyediaan barang dan jasa (Kay, Roy, \& Donaldson, 2016). Walaupun tetap marjinal social enterprise pada nyatanya tetap membutuhkan promosi agar banyak warga mengenal dan perusahaan tersebut dapat berjalan.

Promosi dianggap sebagai elemen yang sangat penting dari pekerjaan (Busari, Mughal, \& Naw, 2017). Dengan beberapa cara khusus social enterprise diperkenalkan dengan efektif kepada masyarakat, dengan hal hal lain dapat dicapai seperti informasi berharga dan kerjasama dengan pihak lain disamping reputasi. Social enterprise memperkenalkan berbagai kegiatan, seperti seminar, workshop, pameran, atau kompetisi dengan tujuan mempromosikan social enterprise. Sebuah social enterprise bisa bergabung dengan beberapa workshop yang diadakan oleh organisasi lain, yang menampilkan fungsi untuk mengakses informasi. Bergabung dengan aktifitas international menyebabkan perusahaan mendapatkan reputasi yang bagus dan meningkatkan kemampuan serta memperluas akses perusahaan (Pratono, Marciano, \& Suyanto, 2018). 


\section{Bibliography}

Busari, A. H., Mughal, Y. H., \& Naw, S. (2017). Analytical cognitive style moderation on promotion and turnover intention. 36(3), 438-464.

Gammoh, B. S., \& Voss, K. E. (2013). Alliance competence: The moderating role of valence of alliance experience. European Journal of Marketing, 47(5/6), 964-986.

Hamister, J. W. (2012). Supply chain management practices in small retailers. International Journal of Retail \& Distribution Management, 40(6), .427-450.

Ishido, H. (2017). Global value chains and liberalization of trade in services: Implications for the Republic of Korea. Journal of Korea Trade, 21(1), 38-55.

Kay, A., Roy, M. J., \& Donaldson, C. (2016). Re-imagining social enterprise. Social Enterprise Journal, $12(2), 217-234$.

Lee, J., \& Gereffi, G. (2015). Global value chains, rising power firms and economic and social upgrading. critical perspectives on international business, 11(3/4), 319-339.

Pratono, A. H. (2019). Cross-cultural collaboration for inclusive global value chain: a case study of rattan industry. International Journal of Emerging Markets. doi: https://doi.org/10.1108/ IJOEM-012017-0028

Pratono, A. H., \& Ratih, R. V. (2019). International Alliance Strategies: A Case Study of the Indonesian Medical Device Industry. Globalization and Development, Contributions to Management Science, 381-400. doi:https://doi.org/10.1007/978-3-030-11766-5_15

Pratono, A. H., Marciano, D., \& Suyanto. (2018). Internationalization of Social Enterprise : Scaling Up the Social Innovation in Indonesia. The 2018 International Conference of Organizational Innovation, KnESocialSciences, 362-370. doi:10.18502/kss.v3i10.3387

Tambunan, T. T. (2011). Development of small and medium enterprises in a developing country: The Indonesian case. Journal of Enterprising Communities: People and Places in the Global Economy, $5(1), 68-82$.

Teng, B. S., \& Das, T. K. (2008). Governance structure choice in strategic alliances: The roles of alliance objectives, alliance management experience, and international partners. Management Decision, $46(5), 725-742$. 
Veiga, P. M., \& Franco, M. (2015). Alliance portfolios and firms' business strategy: a content analysis approach. Management Research Review, 38(11), 1149-1171.

Wong, A., Wei, L., \& Wang, X. (2018). Collectivist values for constructive conflict management in international joint venture effectiveness. International Journal of Conflict Management, 29(1), 126-143. 